\title{
The contribution of copyright-based industries to the South African economy
}

AUTHORS:

Anastassios Pouris 1

Roula Inglesi-Lotz ${ }^{2}$

\section{AFFILIATIONS:}

IInstitute for Technological

Innovation, University of Pretoria,

Pretoria, South Africa

${ }^{2}$ Department of Economics,

University of Pretoria, Pretoria,

South Africa

\section{CORRESPONDENCE TO:}

Roula Inglesi-Lotz

\section{EMAIL:}

Roula.Inglesi-Lotz@up.ac.za

\section{DATES:}

Received: 20 Sep. 2016

Revised: 27 Mar. 2017

Accepted: 04 July 2017

\section{KEYWORDS:}

economic impact; intellectual property rights; multipliers; creative industries; WIPO

\section{HOW TO CITE:}

Pouris A, Inglesi-Lotz R. The contribution of copyrightbased industries to the South African economy. S Afr J Sci. 2017;113(11/12), Art. \#2016-0286, 7 pages. http://dx.doi.org/10.17159/ sajs.2017/20160286

\section{ARTICLE INCLUDES: \\ $\times$ Supplementary material \\ $\times$ Data set}

\section{FUNDING:}

World Intellectual Property Organization
(C) 2017. The Author(s). Published under a Creative Commons Attribution Licence.
We report the results of an effort to measure the contribution of copyright-based industries to the South African economy. Following the methodology of the World Intellectual Property Organization, we identify the copyright industry's contribution to GDP, employment, imports and exports in South Africa for the period 1970-2009. It was estimated that the sector contributed 4.1\% to GDP - more than the contributions of other sectors such as agriculture and food, beverages and tobacco. Because of this quantified importance of the copyright-based industries, we recommend that relevant South African policy authorities and policymakers should monitor and publicise regularly the performance of the copyright-based industries as well as promote programmes for their development and growth.

\section{Significance:}

- Copyright-based industries have the potential to play an important role in job creation and economic growth.

- $\quad$ Our findings suggest that policymakers should design and promote the implementation of future policies and strategies related to these sectors.

\section{Introduction}

In current modern economies, knowledge is considered to be an influential aspect of economic growth and development as it contributes to the improvement of all the other traditional factors of production: capital, labour, technological progress and entrepreneurship. The creation of new knowledge is highly dependent on the protection of intellectual property. ${ }^{1}$ In essence, the creation and investment of creative and innovative works should be promoted and directed properly and effectively by each country's copyright laws. ${ }^{2}$ However, as specifically discussed by Gani-Ikilama ${ }^{3}$, there are numerous and diverse approaches as to how to define creative industries, and thus the investigation of their impact has not reached consensus ${ }^{4}$.

Industries protected by copyright and related rights are expected to have considerable impact on national economies. Studies that have examined copyright through a legal lens are numerous ${ }^{5,6}$; Yao and Peng ${ }^{6}$, for example, concluded that the leniency of copyright protection may affect the level of benefit thereof for the various stakeholders. However, measuring quantitatively the relevant contribution of copyright-based industries to an economy or region is only a recent phenomenon. Although several international studies have been conducted with regard to the importance of individual copyright industries ${ }^{7,8}$, limited efforts have been made to capture and estimate the economic impact of the copyright-based industries in South Africa. In recent years, the World Intellectual Property Organization (WIP0) and the South African Department of Trade and Industry have supported the collection of data including data on copyright-based activities. At the time of our study, it was only the second study in the African region; the first being a Kenyan study ${ }^{9}$. More recently, similar studies have been completed in Ethiopia and Malawi. ${ }^{10}$

Our objective was to measure and report on the economic role of copyright-based industries in the South African economy through the classification defined and used by WIP0. ${ }^{11}$ The results show the importance of the various sectors and thus have the potential to inform policymakers on the design and implementation of future policies and strategies towards improving the country's growth and development.

Similar studies quantifying the economic contribution of copyright-based industries of developed and developing economies indicate the importance of these industries. The total economic contribution of copyright-based industries as a percentage to GDP varies from $2.81 \%$ in Bulgaria to $11.70 \%$ in the Philippines. Similarly, the indicator ratio of persons employed in the copyright-based sector to the total number of employees in the economy varies from $3.03 \%$ in Jamaica to $11.17 \%$ in Latvia. ${ }^{11}$

\section{Institutional framework on copyright in South Africa}

The Copyright Act, Act No. 98 of 1978 and its amendments legislated copyright for the first time in South Africa. Section 2 of the Act identifies the following as works that are eligible for copyright: literary works, musical works, artistic works, cinematographic films, sound recordings, broadcasts, programme-carrying signals, published editions, and computer programs. ${ }^{11}$

South Africa's commitment to copyright issues and protection of artistic works is demonstrated by the country being party to the Berne Convention for the Protection of Literary and Artistic Works and the Agreement on TradeRelated Aspects of Intellectual Property Rights (TRIPS), as well as being a signatory of the WIPO Copyright Treaty. From a national policy perspective, the country has supported its commitment since 1998. The first strategy dealing with cultural and other copyright-related industries was published by the then Department of Arts, Culture, Science and Technology (DACST), titled Cultural Industries Growth Strategy. ${ }^{12}$ DACST valued this study as its main contribution to the country's Growth, Employment and Redistribution (GEAR) strategy. The DACST strategic plan categorised the following industries as 'cultural': music, craft, publishing, and film and television. These industries were selected for their potential competitive advantage internationally as well as their potential for the creation of jobs and opportunities for rural and urban growth and development. 
The strategy ${ }^{12}$ - as summarised in WIP0 ${ }^{11}$ - makes key recommendations for the future of these industries, stressing the importance of ${ }^{11}$ :

- designing and implementing a Cultural Industries Development Programme (CIDP), setting up a CIDP regulatory framework

- creating a Cultural Industries Development Fund

- $\quad$ promoting the industries internationally and setting up an export programme

- coordinating copyright legislation to protect the local cultural products

- developing human resources and skills appropriate to cultural industries

- $\quad$ adopting and coordinating government supply side measures

- designing and implementing an awareness campaign focused on audience development

- collecting and monitoring statistics

- coordinating initiatives in other departments

- $\quad$ establishing a Cultural Industries Development Agency.

\section{Brief literature review}

WIPO' notes that 'the economic contribution of the copyright-based industries has exceeded expectations in the last two decades'.

To promote related studies in the policy sphere, WIPO ${ }^{13}$ published the Guide on Surveying the Economic Contribution of the Copyright-based Industries. The report provides guidance with regard to the methods as well as relevant indicators for such studies. Figure 1 summarises the contribution of copyright-based industries to selected economies internationally (studies commissioned by WIP0). The percentage of economic output ranges from $2.81 \%$ for Bulgaria to $11.7 \%$ for the Philippines, while that for employment is from $3.03 \%$ in Jamaica to $11.17 \%$ in Latvia.

Studies independent of WIPO have confirmed similar results; for example, Siwek ${ }^{14}$ found that the US copyright-based industries contributed $7.75 \%$ to the country's GDP and 5.9\% of the total labour in 2001.

Looking exclusively at European countries, Media Group ${ }^{15}$ concluded that copyright-based sectors are imperative for economic production and evolution of the labour force in Europe (Figure 2).

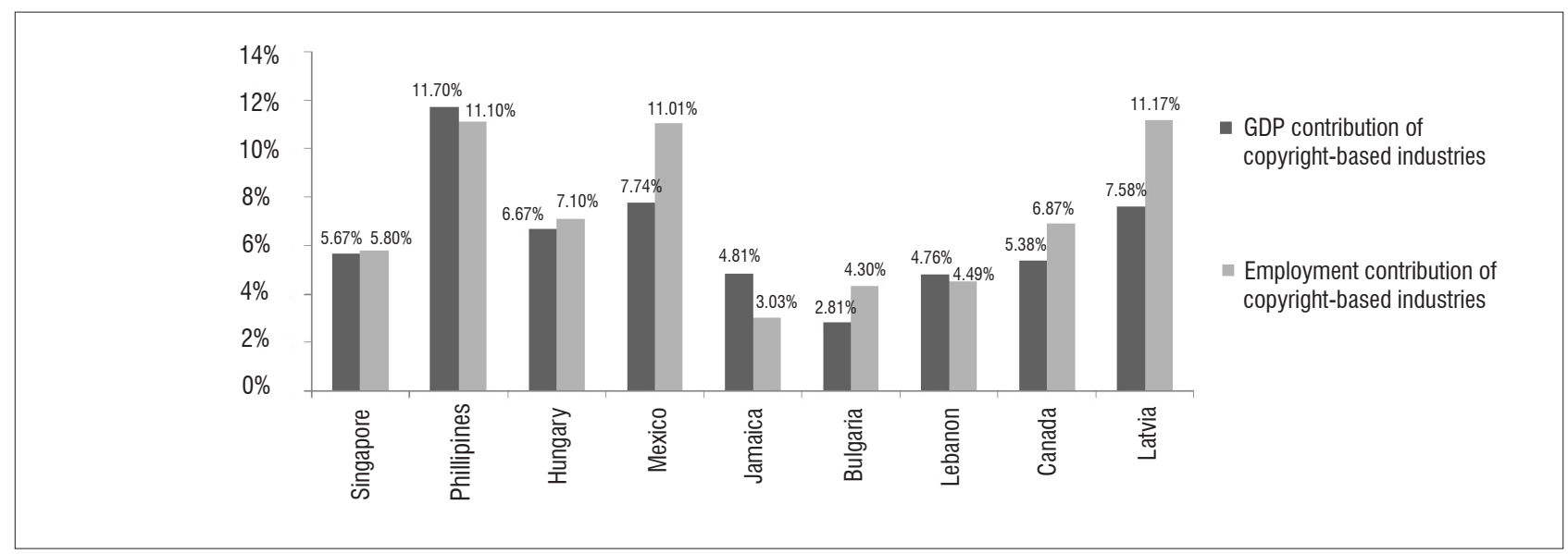

Source: Adapted from WIPO'11

Figure 1: Contribution of copyright-based industries to GDP and employment in various countries.

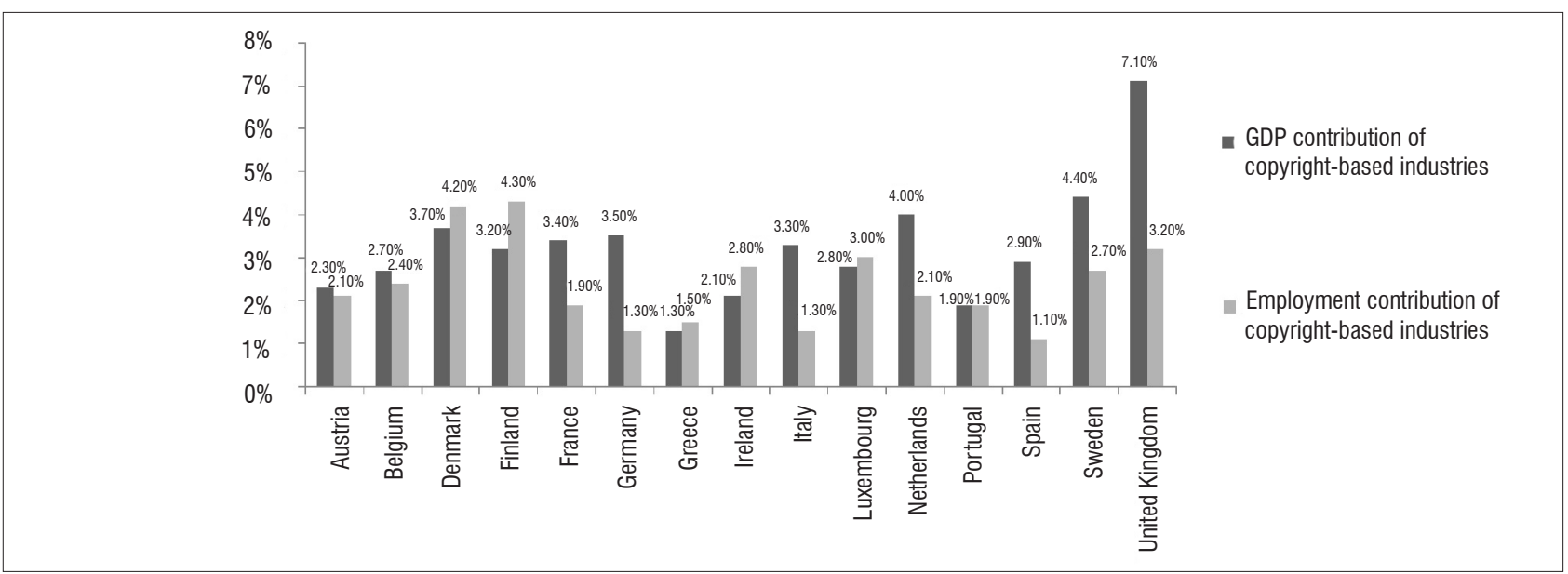

Source: Adapted from WIPO'11

Figure 2: Contribution of copyright-based industries to GDP and employment in countries of the European Union. 
Table 1: Classification of copyright-based industries

\begin{tabular}{l|l|l|l}
\hline \hline \multicolumn{1}{c|}{ Core } & \multicolumn{1}{c|}{ Interdependent } & \multicolumn{1}{c}{ Partial } \\
\hline Printing, publishing and recorded media & $\begin{array}{l}\text { Television, radio and communication } \\
\text { equipment }\end{array}$ & Apparel, textiles and footwear & General wholesale and retailing \\
\hline Film and television industry & $\begin{array}{l}\text { Computers and equipment/ } \\
\text { photocopiers }\end{array}$ & $\begin{array}{l}\text { Furniture/ jewellery/ musical } \\
\text { instruments/ games and toys }\end{array}$ & Transport, storage and communication \\
\hline $\begin{array}{l}\text { Photography/ software and databases/ } \\
\text { advertising }\end{array}$ & Paper and paper products & Crafts & Glass and glass products \\
\hline Copyright collecting societies & &
\end{tabular}

\section{Methodology and data}

As per WIPO ${ }^{13}$, 'copyright-based industries are those engaged in creation, production and manufacturing, performance, broadcast, communication and exhibition or distribution and sales of works and other protected subject matter'. WIPO ${ }^{13}$ explains that 'economic impact can be related to both core copyright-based industries and non-core industries'.

Relative to their level and type of association to copyright, the main copyright-based industries are categorised into four sub-industries ${ }^{13}$.

- Core copyright industries: industries wholly engaged in creation, production and manufacturing of performance, broadcast, communication and exhibition or distribution and sales of works and other protected subject matter.

- Interdependent copyright industries: industries engaged in production, manufacture and sale of equipment whose function is wholly or primarily to facilitate the creation, production or use of works and other protected subject matter.

- Partial copyright industries: industries in which a portion of the activities is related to works and other protected subject matter and may involve creation, production and manufacturing, performance, broadcast, communication and exhibition or distribution and sales.

- $\quad$ Non-dedicated support industries: industries in which a portion of the activities is related to facilitating, broadcast, communication, distribution or sales of works or other protected subject matter and whose activities have not been included in the core copyright industries.

Table 1 presents the South African sub-sectors that were classified as copyright-based industries and includes the specific categories to which they belong.

The basic data sources for the analysis were: Business Monitor International Ltd; Department of Arts, Culture, Science and Technology; Department of Labour; Economist Intelligence Unit; National Organisation for Reproduction Rights in Music in Southern Africa (NORM); Publishers Association; Quantec databases; SA Recording Rights Association Ltd (SARRAL); South African Book Development Council (SABDC); South African Reserve Bank; South African Revenue Service (SARS); Southern African Music Rights Organisation (SAMRO) and Statistics South Africa. ${ }^{11}$

To evaluate and quantify the copyright content for various industries, we used the copyright factor. This factor is defined as the percentage ratio of copyright activities in a given industry. Various methodologies for the estimation of this factor are available in the literature. We used the method of the Singaporean case study ${ }^{1}$ (see Table 2) because Singapore is also a newly industrialised economy that depends on its trade and other copyright-related industries. Also, the two countries have similar copyright legislation, intellectual property rights laws and piracy rates. ${ }^{16,17}$
All core copyright-based industries, as shown in Table 1, have a copyright factor of $1(100 \%)$; all the non-dedicated support industries have a copyright factor of 0.057 . For the interdependent industries, the copyright factor varies from 0.25 (paper and paper products) to 0.35 (television, radio and communication as well as computers and equipment), while for the partial copyright-based industries, the variation is much higher: from 0.420 (crafts) to 0.004 (apparel, textiles and footwear).

\section{Empirical results}

The first part of the quantitative analysis is a presentation of a share of the various indicators to the total economy. Figure 3 quantifies the economic importance of the copyright-based industries in 2009. The total copyright-based industries sector contributes as much as $4.1 \%$ to the total South African economy. Among the sub-sectors of copyrightbased industries, the core industries contributed $2.05 \%$, the nondedicated industries $1.29 \%$, the interdependent industries $0.56 \%$ and the partial industries $0.21 \%$. The total copyright-based industries employed $4.08 \%$ of the country's workforce. As far as exports are concerned, the share of the copyright-based industries was at a similar level (4.07\%), and for imports, the total copyright-based industries' contribution was approximately double that of the other indicators $(7.85 \%)$ - a finding that is not that surprising, especially for countries that have a low high-tech manufacturing base.

The contribution of copyright-based industries in total to the economy's value added showed a constant trend at about $4 \%$ for the period 1970 2008 (Figure 4); the same trend was observed in the imports' contribution of the copyright-based industries. In contrast, the industries' contribution to the country's exports and employment showed an increasing trend for the period 1970-2009. The difference in contributions between imports and exports could be attributed to the higher local share of production of interdependent copyright-based industries as a result of the development of advanced technologies in the digital age.

To disaggregate these trends further, Table 2 presents the growth of the shares of each of the various main categories of copyright-based industries to the total economies in terms of value added, employment, imports and exports. These figures are presented in year-on-year growth rates of the contribution. For value added, in all the sub-divisions, the observed trend was growth in the last decades, with the exception of the partial copyright-based industries which experienced a decrease of $33 \%$ during the 1990s. In terms of employment, the interdependent copyright industries showed a decrease over the last two decades, while the other industries showed a continuous increase in their share. For imports and exports, the growth rates of the shares of all copyright-based industries were significantly higher than those of the rest of the indicators, showing how volatile the trade of these industries are in South Africa. In addition, the trends followed the overall South African trade, specifically with respect to increases in the 1990s after the end of sanctions.

As mentioned, the partial copyright-based industries decreased their share in total value added in the 1990s. Combining this trend with a significant increase in imports (175\%) and an increase - albeit slower - in exports $(18 \%)$ in the same period, one can conclude that the 


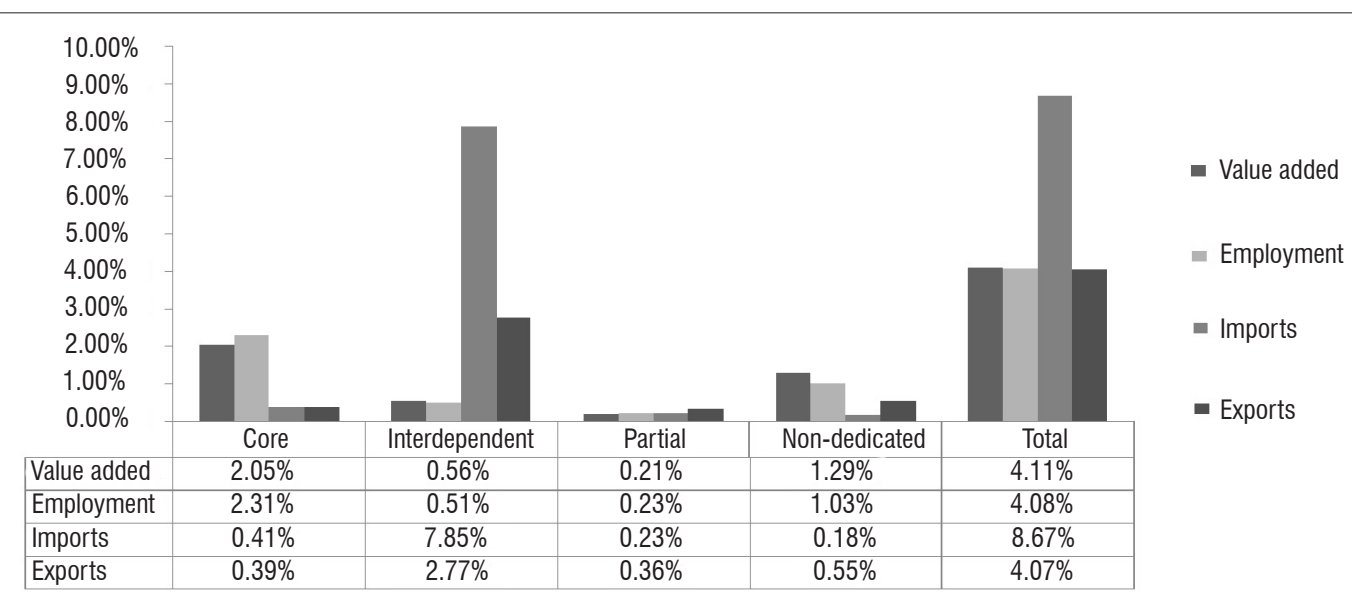

Source: Adapted from WIPO'11

Figure 3: Contribution of the different categories of copyright-based industries to the South African economy in 2009.

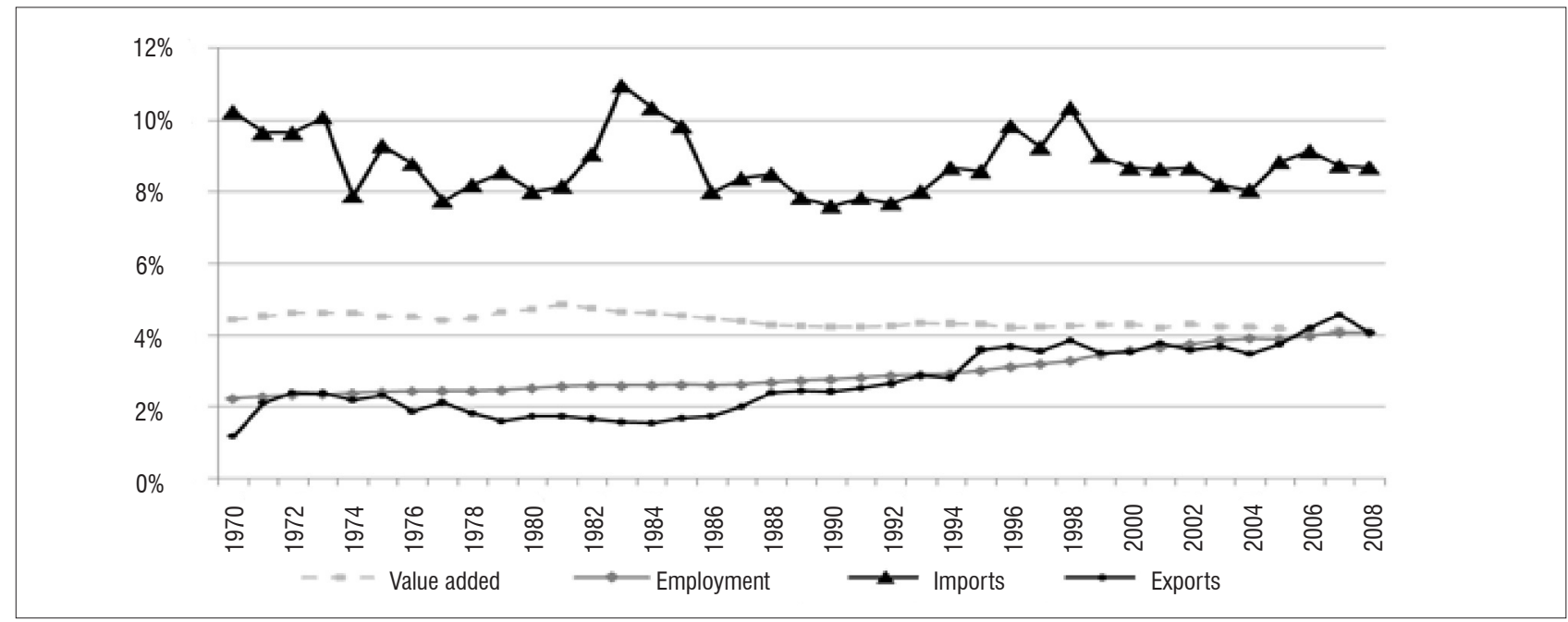

Source: Adapted from WIPO'11

Figure 4: Contribution of copyright-based industries to the South African economy (value added, employment, imports and exports) from 1970 to 2008.

industries presented a lack of comparative advantage of their product in comparison with the rest of the world. That might also explain the negative growth in employment during the 2000s.

By comparison, the core copyright industries experienced a decrease $(-29 \%)$ in imports and a large increase $(108 \%)$ in exports in the same period, indicating that the sector is relatively competitive with the rest of the world. In addition, the growth rate of the employment share has steadily increased through the decades - almost hand in hand with the value added trends.

Even though the share of value added of the interdependent industries showed an increasing trend through the years, the employment share showed a negative growth during the last two decades of the period under assessment. The reason for this finding might be that these industries became more capital intensive (with less need for human capital). Globalisation, technological progress and know-how transfer could be reasons for that transformation. So why were the other industries not significantly affected by these phenomena? Possibly because the other copyright-based industries are less technology driven.

A basic input-output analysis was used to estimate the direct and indirect effects of the total copyright-based industries to the South African economy. Table 3 shows the production-induced effect of a number of industries on total output. The multiplier illustrates how much a sector should increase its inputs (both internally and other sectors) to produce one extra unit of product to meet an increase in final demand of ZAR1 (first-round effects). The industrial support effect shows how much various industries should increase their purchase to increase their output by that much to meet the first-round requirements. ${ }^{11}$ The figures show that the copyright-based industries are not a negligible factor/sector in the South African economy and can actually make a difference.

To put these findings in perspective, the analysis proceeds with a comparison with other main sectors in South Africa's economy (Figure 5). Copyright-based industries contributed, unsurprisingly, less to value added than manufacturing (18.36\%) and mining (6.15\%), but more than agriculture $(2.51 \%)$ and food, beverages and tobacco $(3.09 \%)$ in 2008 . The copyright-based industries employed less labour than the mining, manufacturing and agriculture sectors $(4.96 \%$, $12.47 \%$ and $7.27 \%$ respectively) but more than the food, beverages and tobacco sector $(1.96 \%)$ in the same year. Finally, with respect to the trade potential of the copyright-based industries, these industries contributed more (4.07\%) to the country's exports than the agriculture and food, beverages and tobacco sectors (both below 4\%), although still not an amount comparable with those of the main exporters of the country: manufacturing and mining. Similar results emerge from the imports comparison. 
Table 2: Copyright-based industries' growth of share to the economy of value added, employment, imports and exports from 1970 to 2008

\begin{tabular}{|c|c|c|c|c|c|}
\hline & \multicolumn{4}{|c|}{ Value added } & \multirow{2}{*}{ Total } \\
\hline & Core & Interdependent & Partial & Non-dedicated & \\
\hline 1970-1979 & $28 \%$ & $63 \%$ & $36 \%$ & $44 \%$ & $37 \%$ \\
\hline 1980-1989 & $3 \%$ & $20 \%$ & $94 \%$ & $18 \%$ & $8 \%$ \\
\hline 1990-1999 & $17 \%$ & $15 \%$ & $-6 \%$ & $31 \%$ & $16 \%$ \\
\hline \multirow[t]{3}{*}{ 2000-2008 } & $24 \%$ & $40 \%$ & $24 \%$ & $45 \%$ & $33 \%$ \\
\hline & \multicolumn{4}{|c|}{ Employment } & \multirow{2}{*}{ Total } \\
\hline & Core & Interdependent & Partial & Non-dedicated & \\
\hline 1970-1979 & $33 \%$ & $23 \%$ & $29 \%$ & $21 \%$ & $33 \%$ \\
\hline 1980-1989 & $36 \%$ & $16 \%$ & $30 \%$ & $10 \%$ & $23 \%$ \\
\hline 1990-1999 & $51 \%$ & $-5 \%$ & $12 \%$ & $4 \%$ & $26 \%$ \\
\hline \multirow[t]{3}{*}{ 2000-2008 } & $30 \%$ & $-6 \%$ & $-13 \%$ & $17 \%$ & $21 \%$ \\
\hline & \multicolumn{4}{|c|}{ Imports } & \multirow{2}{*}{ Total } \\
\hline & Core & Interdependent & Partial & Non-dedicated & \\
\hline 1970-1979 & $9 \%$ & $-28 \%$ & $-31 \%$ & $-20 \%$ & $-7 \%$ \\
\hline 1980-1989 & $-17 \%$ & $5 \%$ & $-9 \%$ & $49 \%$ & $-5 \%$ \\
\hline 1990-1999 & $21 \%$ & $231 \%$ & $175 \%$ & $27 \%$ & $104 \%$ \\
\hline \multirow[t]{3}{*}{ 2000-2008 } & $-29 \%$ & $72 \%$ & $160 \%$ & $8 \%$ & $46 \%$ \\
\hline & \multicolumn{4}{|c|}{ Exports } & \multirow{2}{*}{ Total } \\
\hline & Core & Interdependent & Partial & Non-dedicated & \\
\hline 1970-1979 & $-55 \%$ & $10 \%$ & $93 \%$ & $1 \%$ & $15 \%$ \\
\hline 1980-1989 & $-14 \%$ & $130 \%$ & $101 \%$ & $40 \%$ & $84 \%$ \\
\hline 1990-1999 & $202 \%$ & $97 \%$ & $18 \%$ & $100 \%$ & $82 \%$ \\
\hline $2000-2008$ & $108 \%$ & $4 \%$ & $23 \%$ & $50 \%$ & $31 \%$ \\
\hline
\end{tabular}

Table 3: $\quad$ Production-induced effect of copyright-based industries: Results of an input-output analysis of 2009

\begin{tabular}{l|c|c|c|c}
\hline \hline & $\begin{array}{c}\text { Production-induced } \\
\text { effect }\end{array}$ & $\begin{array}{c}\text { Adjusted for } \\
\text { copyright factors }\end{array}$ & $\begin{array}{c}\text { Production-induced } \\
\text { effect }\end{array}$ & $\begin{array}{c}\text { Adjusted for } \\
\text { copyright factors }\end{array}$ \\
\hline \hline Industry & \multicolumn{2}{|c|}{ Outcome } & \multicolumn{2}{|c}{ Employment } \\
\hline Photography/software and databases/advertising & $1.13 \%$ & $0.11 \%$ & $2.97 \%$ & $0.30 \%$ \\
\hline Communication & $1.18 \%$ & $0.07 \%$ & $2.73 \%$ & $0.16 \%$ \\
\hline Crafts ${ }^{\dagger}$ & $0.76 \%$ & $0.32 \%$ & $2.87 \%$ & $1.21 \%$ \\
\hline Film and television ${ }^{\dagger}$ & $1.60 \%$ & $1.60 \%$ & $2.98 \%$ & $2.98 \%$ \\
\hline Footwear & $2.08 \%$ & $0.01 \%$ & $6.23 \%$ & $0.02 \%$ \\
\hline Furniture & $1.93 \%$ & $0.19 \%$ & $6.48 \%$ & $0.65 \%$ \\
\hline Glass and glass products & $1.49 \%$ & $0.01 \%$ & $4.89 \%$ & $0.03 \%$ \\
\hline Computers and equipment/photocopiers & $1.70 \%$ & $0.06 \%$ & $4.93 \%$ & $0.17 \%$ \\
\hline Other manufacturing & $1.23 \%$ & $0.12 \%$ & $3.65 \%$ & $0.37 \%$ \\
\hline Paper and paper products & $2.02 \%$ & $0.50 \%$ & $5.77 \%$ & $1.44 \%$ \\
\hline Printing, publishing and recorded media & $1.79 \%$ & $1.79 \%$ & $5.17 \%$ & $5.17 \%$ \\
\hline Television, radio and communication equipment & $1.64 \%$ & $0.57 \%$ & $4.75 \%$ & $1.66 \%$ \\
\hline Textiles & $1.81 \%$ & $0.01 \%$ & $6.05 \%$ & $0.02 \%$ \\
\hline Transport and storage & $1.19 \%$ & $0.07 \%$ & $3.02 \%$ & $0.17 \%$ \\
\hline Wearing apparel & $1.59 \%$ & $0.01 \%$ & $6.19 \%$ & $0.02 \%$ \\
\hline Wholesale and retail trade & $1.00 \%$ & $0.06 \%$ & $2.63 \%$ & \\
\hline Total & & $5.49 \%$ & & $14.52 \%$ \\
\hline
\end{tabular}

Source: Adapted from WIPO'1

${ }^{+}$Denotes industries with extrapolated figures 

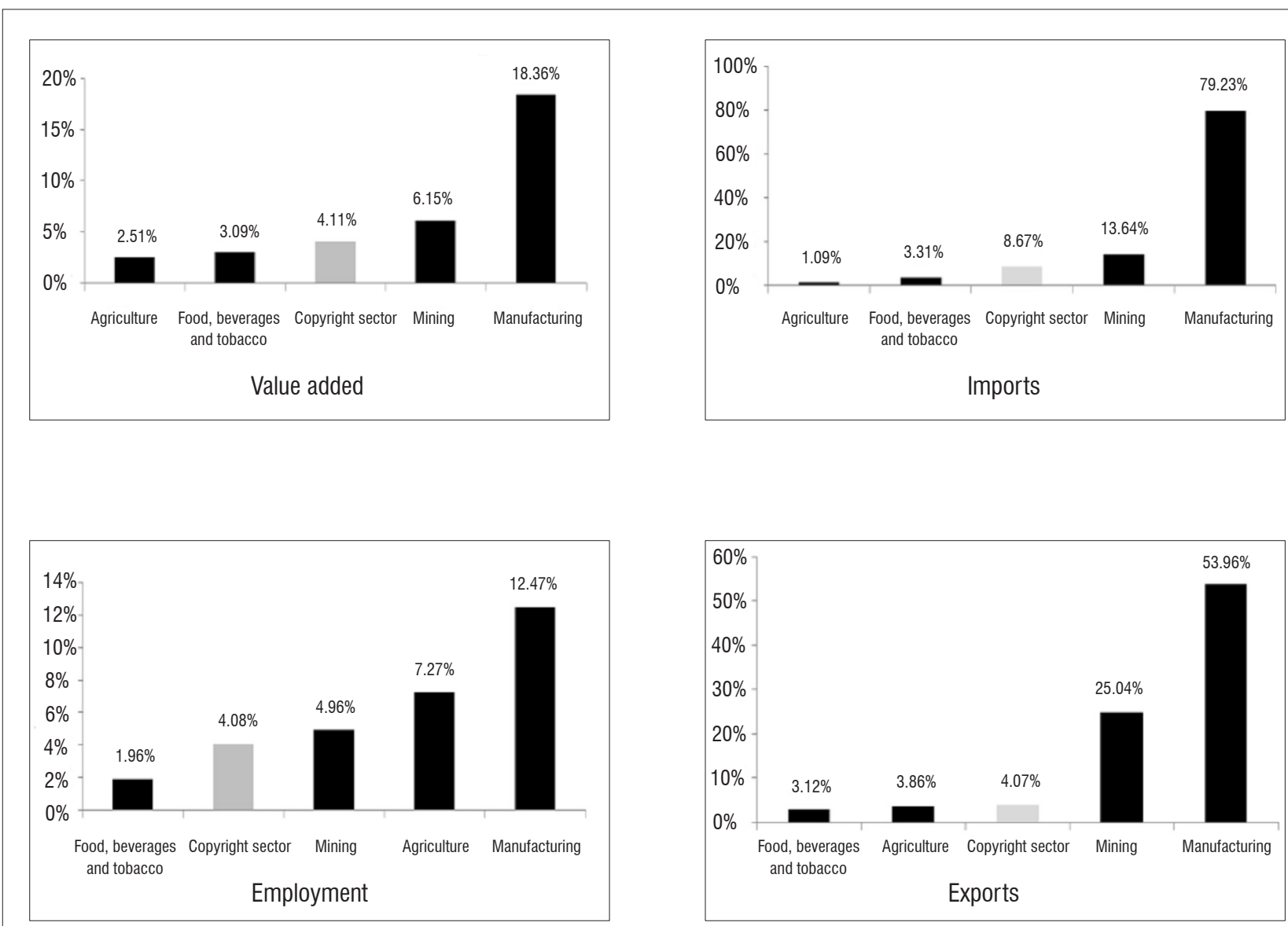

Source: Adapted from WIPO'11

Figure 5: Comparison of the contribution to the economy of copyright-based industries with those of the main economic sectors in South Africa in 2008.

\section{Discussion}

Our aim was to quantify the importance of copyright-based industries to the South African economy. The findings indicate that the contribution of these industries to value added, employment and trade should not be neglected: as expected they could not of course overpass the dominant sectors of the economy (mining and manufacturing) but they outperformed the 'agriculture' and 'food, beverages and tobacco' sectors. Our results are in agreement with those of Manfredi et al. ${ }^{18}$ who showed that copyright-related industries play an important role in a country's economic growth and employment trends.

\section{According to WIPO ${ }^{11}$ :}

The copyright-based industries are responsible for almost $4.11 \%$ of the total economy in terms of value added, with core copyright-based industries being the highest contributor (2.05\%) and the non-dedicated copyright industries following with $1.29 \%$. As far as employment is concerned, $4.08 \%$ of the workforce is employed in the copyright-based industries; the majority of which is employed in the core and non-dedicated copyright-based industries $(2.31 \%$ and $1.03 \%)$. The interdependent copyright-based industries show a high contribution in the exports of the economy $(2.77 \%)$ and an even higher contribution to the total imports (7.85\%).
Efforts have been coordinated and supported locally and internationally (primarily by WIPO) in quantifying the relevant effect on the economy. The economic structure and the promotion and incentives offered for the expansion and development of these industries are crucial factors. In addition, a shortage of relevant data hinders the country's already limited expertise in investigating the sectors based on copyright. Hence, it is suggested the relevant South African policy authorities and policymakers, such as the Department of Trade and Industry, monitor and publicise regularly the performance of the copyright-based industries and promote programmes for their development and growth..$^{19,20}$ Furthermore the country's funding agencies should support research related to copyright coefficients and the operations of the copyright industry.

\section{Acknowledgements}

This investigation was undertaken with the financial and intellectual support of WIPO. The article is based on a relevant WIPO report. We thank WIPO for their support and guidance.

\section{Authors' contributions}

The authors contributed equally to this study. R.I-L. provided expertise in quantitative analysis and A.P. provided expertise in policy implementation.

\section{References}

1. World Intellectual Property Organisation (WIPO). National studies on assessing the economic contribution of the copyright-based industries no. 1: The economic contribution of copyright-based industries in Singapore 2004. Singapore: WIP0; 2006. 
2. Cvetkovski T. Global governance: Regulation of copyright law and policy in popular media copyright industries. In: Copyright and popular media. London: Palgrave; 2013. p. 53-88. https://doi.org/10.1057/9781137024602_2

3. Gani-Ikilama M. Copyright theory and a justificatory framework for creative autonomy in cultural industries. Queen Mary J Intelle. 2016;6(2):154-174. https://doi.org/10.4337/qmjip.2016.02.02

4. Chen L. China's creative industries: Copyright, social network markets and the business of culture in a digital age. New Media Soc. 2013;15(1):157158. https://doi.org/10.1177/1461444812459453d

5. Scaria AG. Piracy in the Indian film industry: Copyright and cultural consonance. Cambridge: Cambridge University Press; 2014. https://doi. org/10.1017/CB09781107588325

6. Yao JJ, Peng H. Copyright protection and cultural industry - Theoretical and empirical studies [article on the Internet]. c2014 [cited 2017 Mar 27]. Available from: http://citeweb.info/20142401529

7. Dobusch L, Schussler E. Copyright reform and business model innovation: Regulatory propaganda at German music industry conferences. Technol Forecast Soc. 2014;83:24-33. https://doi.org/10.1016/j. techfore.2013.01.009

8. Ericsson S. The recorded music industry and the emergence of online music distribution: Innovation in the absence of copyright (reform). George Wash Law Rev. 2011;79(6):1783-1813.

9. Nyariki D, Wasonga 0, Otieno C, Ogadho E, Ikutwa C, Kithinji J. The economic contribution of copyright-based industries in Kenya. Nairobi: World Intellectual Property Organization; 2009.

10. Nicholson RD, Kawooya D. The impact of copyright on access to public information in African countries: A perspective from Uganda and South Africa. In: Proceedings of the World Library and Information Congress: 74th IFLA General Conference and Council; 2008 August 10-14; Quebec, Canada. Quebec: IFLA; 2008. p. 1-24.
11. World Intellectual Property Organization (WIPO). The economic contribution of copyright-based industries in South Africa. Pretoria: WIPO; 2011.

12. South African Department of Arts, Culture, Science and Technology (DACST). Cultural industries growth strategy. Pretoria: DACST; 1998.

13. World Intellectual Property Organization (WIP0). Guide on surveying the economic contribution of the copyright-based industries. Geneva: WIPO; 2003

14. Siwek SE. The measurement of copyright industries: The US experience. Rev Econ Res Copyright Issues. 2004;1(1):17-25.

15. Media Group. The contribution of copyright and related rights to the European economy. Turku: Business Research and Development Centre, Turku School of Economics and Business Administration; 2003.

16. BSA-IDC. Sixth annual BSA-IDC global software: 08 Piracy study. Washington DC: Business Software Alliance; 2009. Available from: http://global.bsa.org/ globalpiracy2008/studies/globalpiracy2008.pdf

17. Property Rights Alliance. The international property rights index [homepage on the Internet]. c2017 [cited 2017 Mar 27]. Available from: http:// internationalpropertyrightsindex.org/

18. Manfredi S, Ricci F, Nappo F, Gilvari IS. Economic contribution of the intensive copyright industries: Theoretical and practical implications in Italy. Technol Innov Educ. 2016;2(1):1-17. https://doi.org/10.1186/s40660-015-0007-8

19. He T. What can we learn from Japanese anime industries? The differences between the domestic and oversea copyright protection strategies towards fan activities. Am J Comp Law. 2014:62:4. https://doi.org/10.5131/ AJCL.2014.0029

20. Cheung M. Copyright challenges facing the website design industry: A survey with creative directors in Hong Kong. Des J. 2014;17(2):291-313. https:// doi.org/10.2752/175630614X13915240576149 